\title{
Comparison Sequences of Pick and Place System Controlled Using PLC
}

\author{
Shahad Sarmad Khaleel ${ }^{1}$, Maher Yahya Salloom ${ }^{2}$, Ahmed Zidan Mohammed ${ }^{3}$
}

\section{Authors affiliations: \\ 1*) Dep. of Automated \\ Manufacturing Engineering, Al- \\ Khwarizmi College of Eng., University of Baghdad, Iraq. Shahadsarmad36@gmail.com}

2*) Dep. of Mechatronics Engineering, Al-Khwarizmi College of Eng., University of Baghdad, Iraq. drmahir@kecbu.uobaghdad.edu.iq

$\left.3^{*}\right)$ Dept. of Automated Manufacturing Engineering, AlKhwarizmi College of Eng., Baghdad University, Iraq. ahmadhzaam@yahoo.com

\section{Paper History:}

Received: $20^{\text {th }}$ July 2020

Revised: $14^{\text {th }}$ Aug. 2020

Accepted: $21^{\text {st }}$ Nov. 2020

\section{Introduction}

In most industrial and factory, the automation become one of the important parts because it reduces time required also need minimum number of labors to operate the machine which led to increase in profit. In spite of the simplicity of the pneumatic system, it still needs automation to get the best results with high speed with maintain the high quality of the product. The pneumatic system components can control by PLC which control the valves, actuator and so on [1]. A large number of industrial applications require the attainment of a new position without continuous control throughout the move. Many of these operations consist of simple movements that can be achieved by actuators

\begin{abstract} sequences. A pick-place system implemented with pneumatic linear doubleacting cylinders to applicator in automated systems processes for manufacturing. The challenge of 3 -axes movement control was achieved using the PLC (Programmable Logic Controller) controller such that the merging between two or three axes was achieved according to the selected sequence of the program. The outcomes show the contrasted sequences and the reference in a constant velocity. The main variable parameter is the number of steps for red sequence. The combination of two axes has developed the sequence and factors in moving products industry is the smooth product's movement, because any high speed might cause a vibration in the system and lead to a decreased positioning accuracy.
\end{abstract}

Keywords: Pick and Place System, Pneumatic, PLC, PPS, Automation.

$$
\begin{aligned}
& \text { مقارنة بين تسلسل العمليات لنظام الكنقاط والوضع من خلال السيطرة } \\
& \text { بواسطة المتحكى المنطقي المبروج } \\
& \text { شهد سرمد خليل ، ماهر يميى سلوم، أمد زيدان محمد المبرمي }
\end{aligned}
$$

يعتبر نظام Pick and place أحد الوظائف المهمة للروبوتات الحديثة المستخدمة في البيئات الصناعية. الهدف

من هذا البحث هو إجراء مقارنة بين التسلسلات الزمنية من خلال الجمع بين محاور متعددة من التسلسلات.

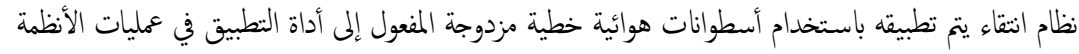

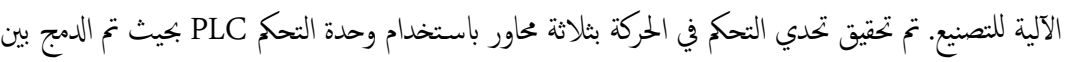

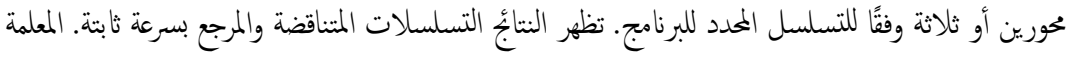

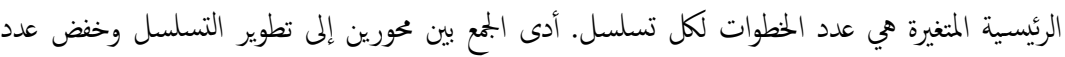

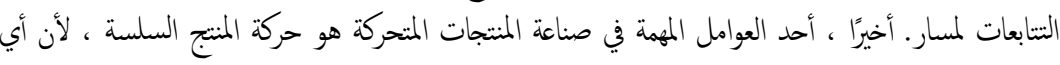

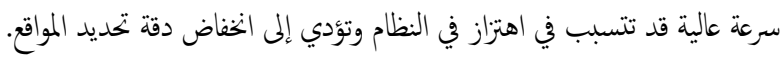

NJES is an open access Journal with ISSN 2521-9154 and eISSN 2521-9162

This work is licensed under a Creative Commons Attribution-NonCommercial 4.0 International License 
Thus, the packaging machine works as an eventbased system in on/off environment.

R, Pawar and, N. R. Bhasme, 2016 [5] Developed little modular structures in comparison with prior structures that have increased the flexibility of PLC configuration, PLC compute, data processing, scan the time, network connection, illustrations show, and different capacities.PLC sequence program consisted of normally open and normally closed contacts associated in equal or in series.

S. Kazemi and, H. Kharrati, 2017 [6] Designed and implementation of a robot control framework on a hardware platform dependent on a programmable logic controllers (PLC) robot is designed controller vision-based for rising performance pick and place applications in the bundling work cells.

L. Alboteanu et al, 2018 [7] Designed and developed an automatic sorting and handling of pieces framework that react to the prerequisites of a flexible manufacturing framework. It is controlled by an Arduino Mega2560 microcontroller development system. In comparison to other handling systems, the robot structure is simpler; it performs the transfer of the pieces by only two movements, thus reducing the handling time.

T. Dewi, et al, 2020 [8] Proposed the combination of inverse kinematics method and FLC to control a 4 DOF arm robot manipulator applied in the digital farming system. The proposed method ensures the right design of the mechanical system and the smoothness of the end-effector motion. The output of inverse kinematics gives the precise parameters to design the robot's mechanics and motions.

S. A. Namekar, and R. Yadav, 2020 [?] discussed the application of Programmable Logic Controller (PLC)and Investigated on the applications of PLC's in energy research, engineering studies, industrial control applications and monitoring of plants are reviewed PLC's did have its own limitations, but studies indicate that PLC's have more benefits than limitations. PLC' scan be used for any application. PLC's can be for simple as well as complicated control system.

S. S. Khaleel, et al, 2020 [10] Designed and implemented pick-place pneumatic system based controlled with Arduino, as well as have reduced the sequence in a specific Arduino program and dealed with analog signal from linear potentiometer as an input signal to Arduino controller.

The most important of automated systems is that how to improve and increase production. But there is still need more efforts to improve and develop the work of these systems. The objective of this work is to study time reduction by combining multiple sequences of operations into one process.

\section{Methodology}

The methodology of the proposed system involves a several sequences of activities used in this work to achieve the desired objective. The following block diagram of the working procedure as illustrated in figure (1).

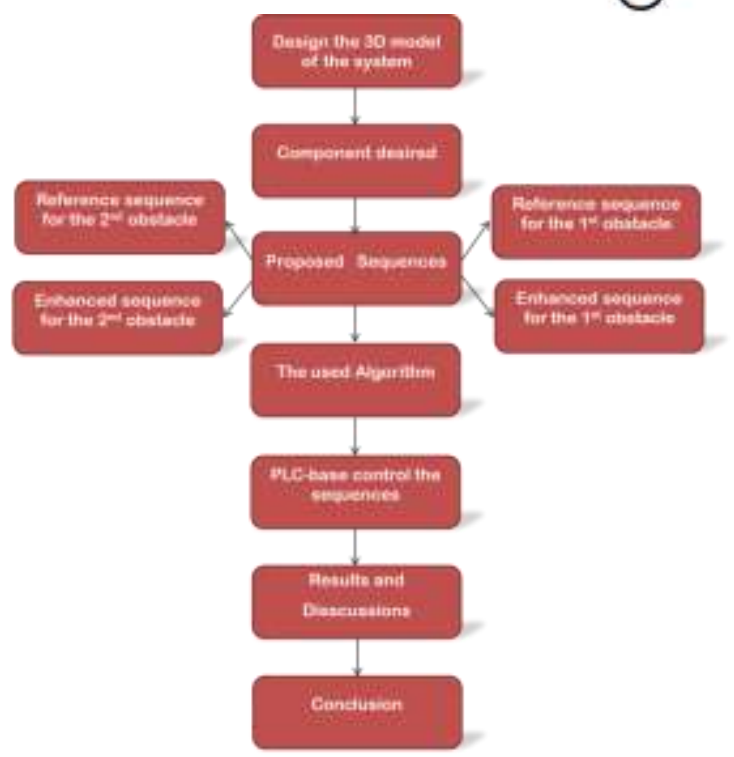

Figure (1): The Proposed Methodology

\subsection{Design the 3D model of the system}

Solid Work is the program that used in this work to design the 3-axis layout of pneumatic cylinders, drawing and assembly of the system components then simulated the 3 -axis motion according to the sequences which will be implemented in a real environment. The 3D - model design of the proposed pick and place system is shown in figure (2).

1- Suction cup of the vacuum gripper.

2- Vacuum generator body.

3- Two of double- acting pneumatic cylinders for Z-axis.

4- Two of double- acting pneumatic cylinders for Y-axis.

5- Six of directional control valves for cylinders (one valve for the extending and one for the retracting in each axis).

6- The 7th directional control valve for vacuum gripper.

7- One of double- acting pneumatic cylinders for $\mathrm{X}$-axis.

8- Plastic pipe for transmitted the compressed air through it.

9- Linear potentiometer for detecting distance for each axis.

10- Overturned T-shape of an aluminum platform.

11- MDF wooden board.

All the measurements were taken by setting axis $(0,0,0)$ as the reference point and are set to be zero position. All directions are chosen to be positive with respect to the axis $(0,0,0)$. The fundamental Dimensions are tabulated in Table1. 


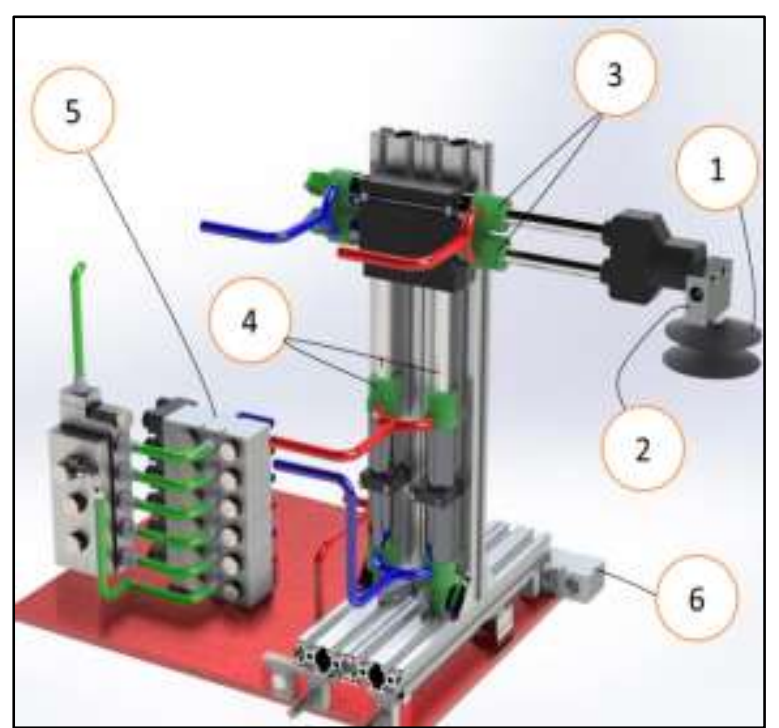

(a)

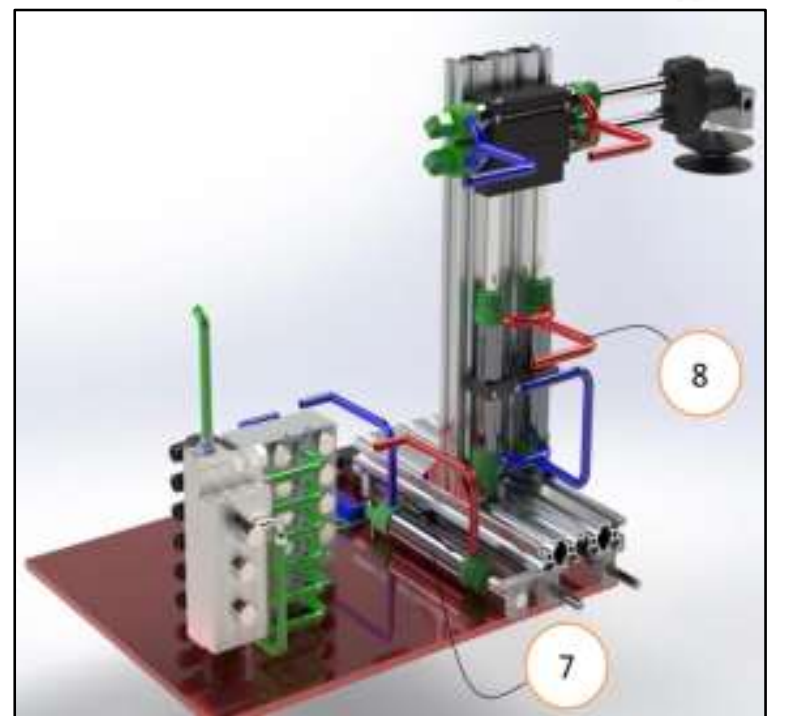

(b)

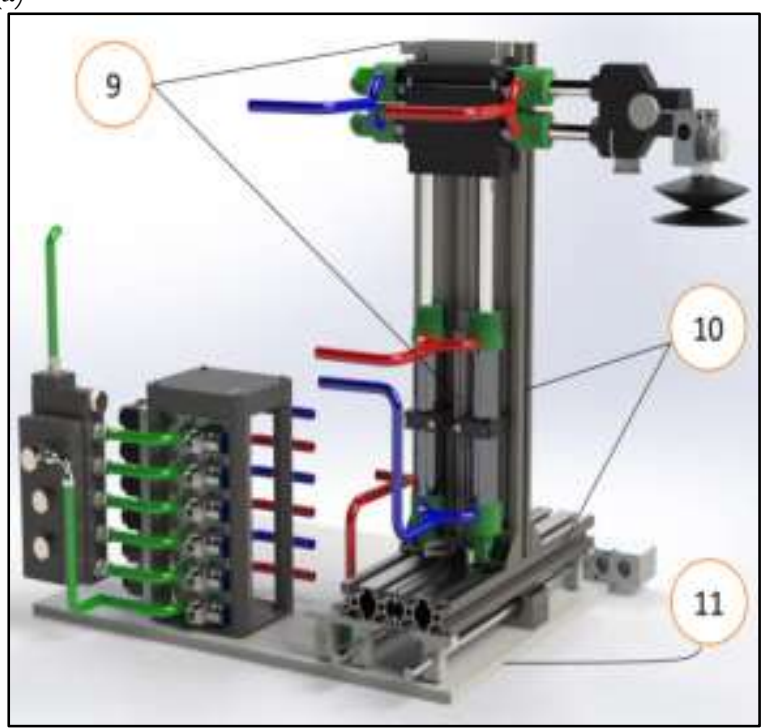

(c)

Figure (2): a), b), and c) The 3D - model design of the proposed pick and place system Table1: Mechanical setting dimensions

\begin{tabular}{|c|c|c|c|c|c|c|c|}
\hline Parameter & $\begin{array}{l}\text { Max. X, Y, } \\
\text { and Z-axes }\end{array}$ & $\begin{array}{l}\text { Min, } X, Y \text {, } \\
\text { and } Z \text {-axes }\end{array}$ & $\begin{array}{l}\text { Gripper } \\
\text { diameter }\end{array}$ & $\begin{array}{c}\text { Piece } \\
\text { diameter }\end{array}$ & $\begin{array}{l}\text { Cylinder } \\
\text { outer } \\
\text { diameter }\end{array}$ & $\begin{array}{l}\text { Cylinder } \\
\text { inner } \\
\text { diameter }\end{array}$ & $\begin{array}{c}\text { Stroke for } \\
\text { all } \\
\text { cylinders }\end{array}$ \\
\hline Dimension / mm & 100 & o & 40 & so & 20 & 10 & 100 \\
\hline
\end{tabular}

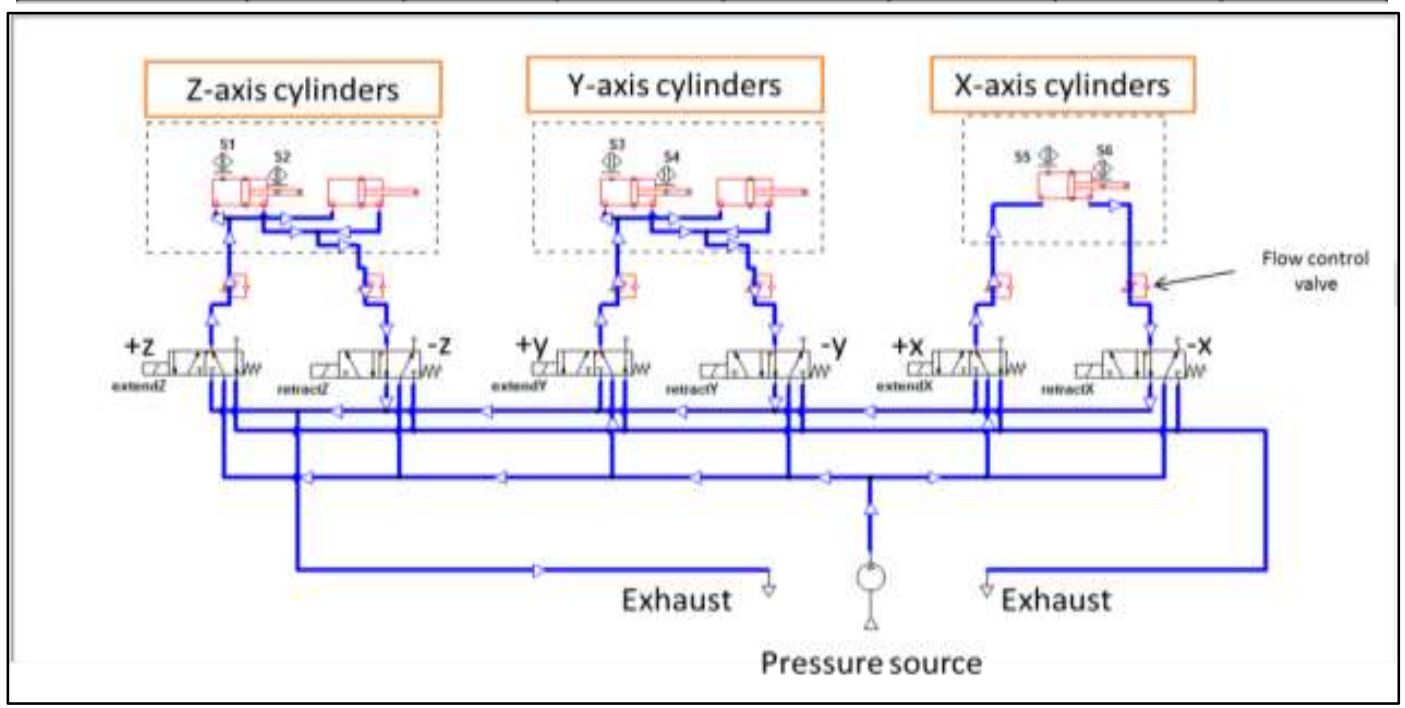

Figure (3): Electro-Pneumatic circuit for all cylinder's system 


\subsection{Components desired}

The proposed system consists of a numeral of mechanical system that assembled together to form the chassis and axes, the following is a detailed listing of the components used in the mechanical part of the proposed system.

1. Compressor: Pressure Source of compressed air. 2. Double acting cylinder: represents the $(X, Y, Z)$ axes.

3. Directional control valve: Actuates the double acting cylinders.

4. Vacuum gripper: grasps and releases the product through pick and place process.

5. Manual air flow valve: Controls the amount of airflow that will eventually dictate the speed and force the pneumatic cylinder will retract or extend.

6. Adjustable Quick Connectors: Nylon tubing it is a quick and reliable connections reusable for multiple connections/disconnections.

There are many devices involved in the configuration of the proposed system that work to control and responsible for simulations between the system and the user these are called electronic components as follows:

There are many devices involved in the configuration of the proposed system that work to control and responsible for simulations between the system and the user these are called electronic components as follows:

1. Linear potentiometer: This Linear Potentiometer Module based on a high-quality linear variable resistor with a maximum resistance of $10 \mathrm{~K} \Omega$.

2. PLC (Programmable Logic Controller): Programmable Logical Controllers are hard component individuals from the PC family, utilizing Integrated Circuits (IC) rather than electromechanical instruments to execute control functions. They are equipped for putting away guidelines, for example, sequencing, timing, math, information control, and interface communication, to control mechanical machines and processes [11].The PLC type used in this work which is SIMENS, SIMATIC, S7-1200. Ladder logic is a programming language that represents a program by a graphical diagram based on the circuit diagrams of relay logic hardware. It was primarily used to develop software for programmable logic controllers (PLCs) used in industrial control applications.

3. Power Supply: A PLC requests power for running, a power supply unit (PSU) is important to change over the voltage, commonly $12-24 \mathrm{~V}$ that enables be utilized to run the PLC. In this work is used (S-75-24 DC 24V 3A) Regulated Switching Power Supply, Input: AC110/220V, Output: DC 24V / 3A.

\subsubsection{Pneumatic System Connection}

Using AUTOMATION STUDIO program for the circuit of each cylinder in the pick and place system which layouts in 3-axis. The electropneumatic circuit, shown in figure (3).

Each cylinder connected with two directional control valves because of these valves are a single solenoid one used for extending the cylinder and the other used for retracting it.

\subsection{Proposed Sequences}

The proposed sequences based on the obstacles that obstruct the path moving of the pick and place system through product transferring.

\subsubsection{The based obstacles}

Based obstacles that the system passes during the transfer of the product from one location to another. There are two obstacles that the system should be avoiding them in specific sequences shows in figure (4), as follows;

\section{- First Obstacle}

The first obstacle should be avoiding overhead it because of its width $=10 \mathrm{~cm}$ larger than its height $=5$ $\mathrm{cm}$.

\section{-Second Obstacle}

In this obstacle, the avoiding has to be from the width because its width $=5 \mathrm{~cm}$ less of its height $=10$ $\mathrm{cm}$.

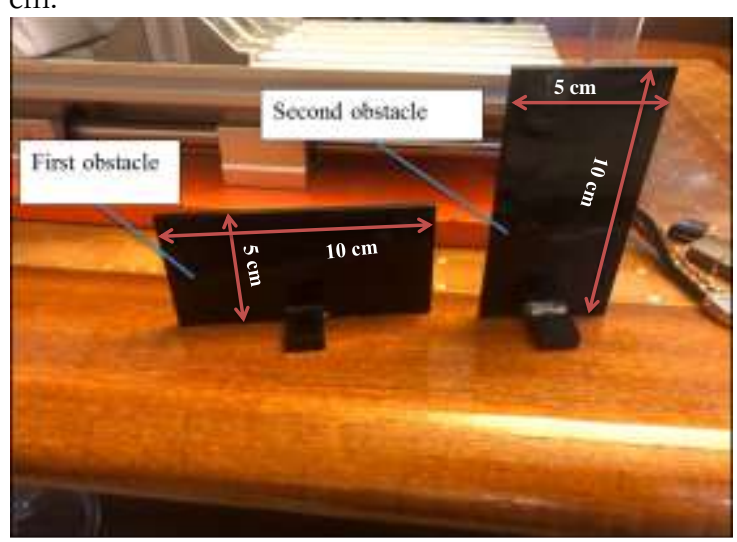

Figure (4): The first and second obstacles.

\subsubsection{Sequences for the Pick and Place system}

The proposed automatic pick and place device works according to the sequences, where the command signals of the pneumatic cylinders are reported for each sequence of the process under the condition imposed by the feedback signals that come from the sensor system.

There are several sequences to perform the pick and place process for each obstacle as follows:

1) Reference Sequence for the first obstacle (Ref-1)

In this process, the obstacle is crossed from the top and left to picking the piece and take it into other side because the width of this obstacle larger than the height of it. After releasing the piece the obstacle is passed from its height to return to the initial position. This sequence corresponded as the reference path for the first obstacle to avoid it by each cylinder moving in a single axis.

In TIA PORTAL program, as in Table (2) shows the PLC tags for addressing and defined the parameters to be able to do the ladder diagram programming of the sequences.

The simulation for the reference sequence of the first obstacle illustrated in figure (5). The same simulation screen appeared for all sequences of the system the different thing is in the number of memory digits that represents the number of the sequence. 
In the ladder diagram of the reference sequence of the first obstacle. The networks represent each sequence in the process. In particular, in figure (6), the sequences 5, 6, and 7 are operated the actuator 1 , the rest of ladder for all actuators and sequences are proposed in the same programming way the difference is which the sensors selected for running the sequence and which the sequence recalled for operating the actuators.

\section{2) Enhanced Sequence for the first obstacle} (YZ)(Enh-1)

For decreasing the sequences of the reference sequence, the two axis $y$, and $z$-axes should be merged in the same time.

Table (3), illustrates the addressing of inputs/outputs of PLC in TIA PORTAL program and described each step of the enhanced sequence for the first obstacle, which is its width larger than its height.

In network 6 , the Ladder diagram of the two merged axes $y$ and $z$ axes are illustrated in figure (7), in this sequence decreasing obtained on the reference sequence which is performed to be eight sequences instead of ten.
3) Reference Sequence for the second obstacle (Ref-2)

The second obstacle is passed from its width in eight sequences to pick the piece and placing it in the other side. This process which is performed in eight sequences is could be the reference for taking it in enhancing process. Addressing and description of $\mathrm{I} / \mathrm{O}$ for PLC in TIA PORTAL program for this sequence is shown in Table (4).

4) Enhanced Sequence for the second obstacle (YZ) (Enh-2)

Here the decreasing also is done by moving two axes in the same instant, in Table (5) shows the addresses and description for this sequence of $\mathrm{I} / \mathrm{O}$ for PLC in TIA PORTAL program.

The enhancing on the reference sequence for each obstacle which is mentioned above that was the velocity of the compressed air for the pick and place system is a constant value. If the velocity of the compressed air changed for any axis to be synchronized with each other axes and to make the three axes reach to the same position in the same time.

\subsection{The Used Algorithm}

To be assurance that the values of the desired parameters are correctly it should be able to support that by making some calculations using many of simple equations, as follows;

Table (2): Addressing and description of the reference sequence for the first obstacle.

\begin{tabular}{|c|c|c|c|c|c|c|c|c|c|}
\hline \multirow{2}{*}{\multicolumn{10}{|c|}{ 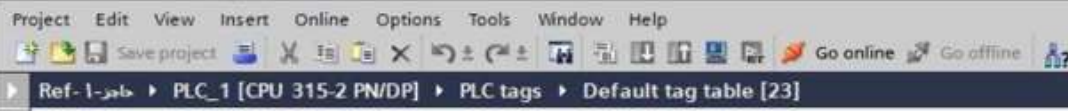 }} \\
\hline & & & & & & & & & \\
\hline \multirow{3}{*}{ 党 } & \multirow{2}{*}{\multicolumn{9}{|c|}{ 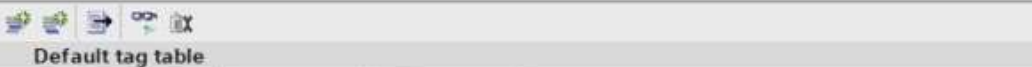 }} \\
\hline & & & & & & & & & \\
\hline & & & & & & lome & ata type & Address & Comment \\
\hline \multirow{23}{*}{ 돌 } & & actuator -1 & $\$ Q 0.0$ & & ב & ctuator - 1 & & $\$ Q 0.0$ & Provides prussure for cylinder in $X$-oxis. \\
\hline & & Actuotor -2 & so0.1 & & 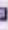 & ctuotor -2 & & so0.1 & Provides prussure for cylinder in $Y$-oxis. \\
\hline & & Actuator -3 & & & a & ictuator - 3 & lool & $\$ 00.2$ & Provides prussure for cylinder in $\mathrm{Z}$-oxis. \\
\hline & & Actuator -4 & & & a & ictuator -4 & 3001 & \$003 & Provides prussure for vaccum gripper. \\
\hline & 5 & s.1 1 & & & a & & 3001 & $\$ 10.4$ & $(+x)$, activates the outstroke of cylinder in $x \rightarrow x$ is \\
\hline & 6 & a 5.2 & & & ב & & 8001 & $\$ 0.5$ & $(-x)$, activates the instroke of cylinder in $X-x$ is \\
\hline & 7 & a s.3 & & & a & & 3001 & $\$ 10.6$ & $(+Y)$, activates the outs troke of cylinder in $Y=x$ is \\
\hline & 8 & $5-4$ & & & 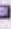 & & sool & $\$ 10.7$ & $(-n)$, activates the instroke of cylinder in $Y-a x i s$ \\
\hline & 9 & a 5.5 & & & a & & 1001 & $\$ 1.0$ & $(+z)$, activates the outs troke of cylinder in $z-a x$ is \\
\hline & 10. & a $5-6$ & & & 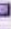 & & 8001 & 3011.1 & $(-2)$, activates the instroke of cylinder in $z \rightarrow x$ xis \\
\hline & 11 & 5.7 & & & a & & 8001 & $\$ 11.2$ & $(O N)$, activates the vaccum gripper to grasp the piece \\
\hline & 12 & a -8 & & & a & -8 & 8001 & $\$ 11.3$ & (OFF), deactivates the vaccum gripper to release the piece \\
\hline & 13 & & & & ב & equence 1 & 3001 & $\operatorname{sen} .4$ & - Y, moves up in $Y$-direction \\
\hline & 14 & Sequence 2 & & & ב & equence 2 & 3001 & 5901.5 & $+\mathrm{Z}$, excends in $\mathrm{z}$ - direction \\
\hline & 15 & Sequence 3 & & & 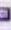 & equence 3 & 3001 & SM1.6 & - $Y$, moves down in $Y$-direction with grosp the piece \\
\hline & 16 & a sequence 4 & & & ב & equence 4 & 3001 & क्91.7 & $+Y$, moves up in $Y$-direction still holding the piece \\
\hline & 17 & Sequence 5 & & & 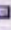 & equence 5 & 2001 & 9412.0 & $+x$, moves to other side in $X$-direction \\
\hline & 18 & Sequence 6 & & & & equence 6 & Bool & EMR.1 & $-Y$, moves down in $Y$-direction and release the piece \\
\hline & 19 & Sequence 7 & & & & equence 7 . & 3001 & SMR.2. & + $Y$, moves up in $Y$-direction \\
\hline & 20 & a Sequence 8 & & & & equence 8 & 3001 & 992.3 & - $X$, return in $x$-direction to the first side \\
\hline & 21 & a Sequence 9 & & & & equence 9 & 3001 & 940,4 & $-\mathrm{z}$, retracts in $\mathrm{z}$-direction \\
\hline & 22 & Sequence 10 & & & & equence 10 & 3001 & $\% \mathrm{MR} .5$ & $\gamma$, finally, moves down in $\gamma$-direction \\
\hline & 23 & Switch & & & & witch & Bool & $\$ 12.6$ & State/5top the sequences \\
\hline
\end{tabular}




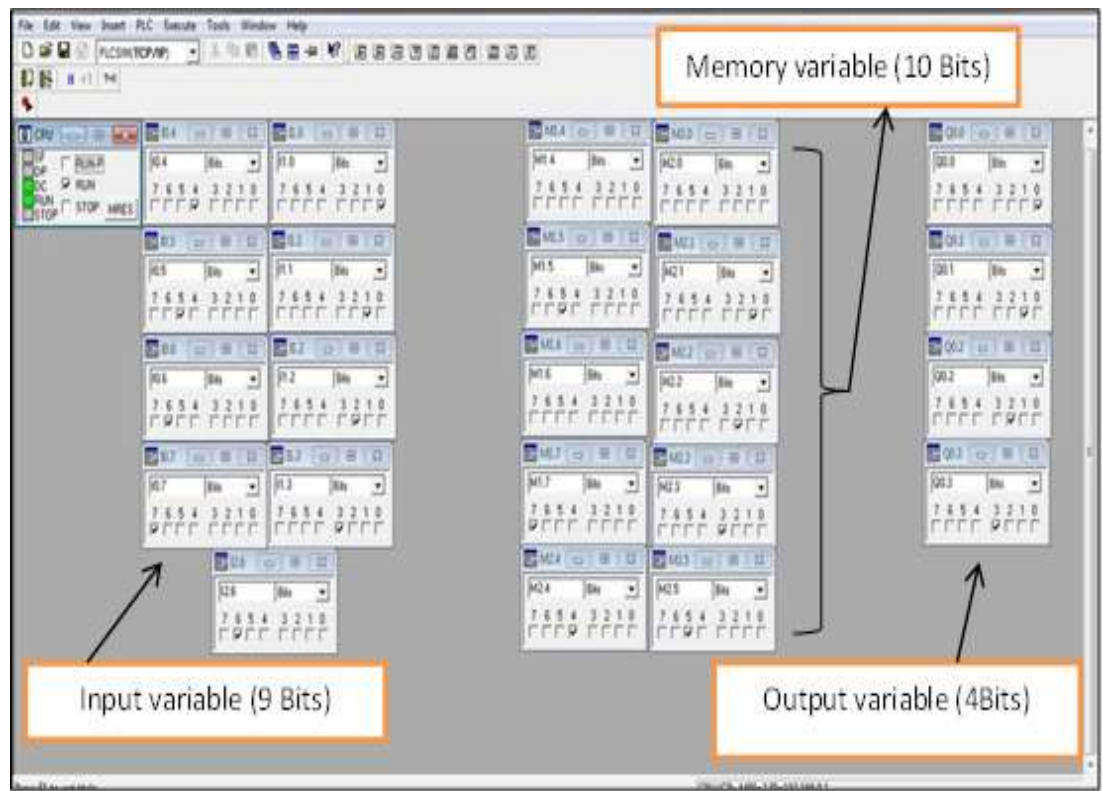

Figure (5): PLC simulation screen for 10 sequences

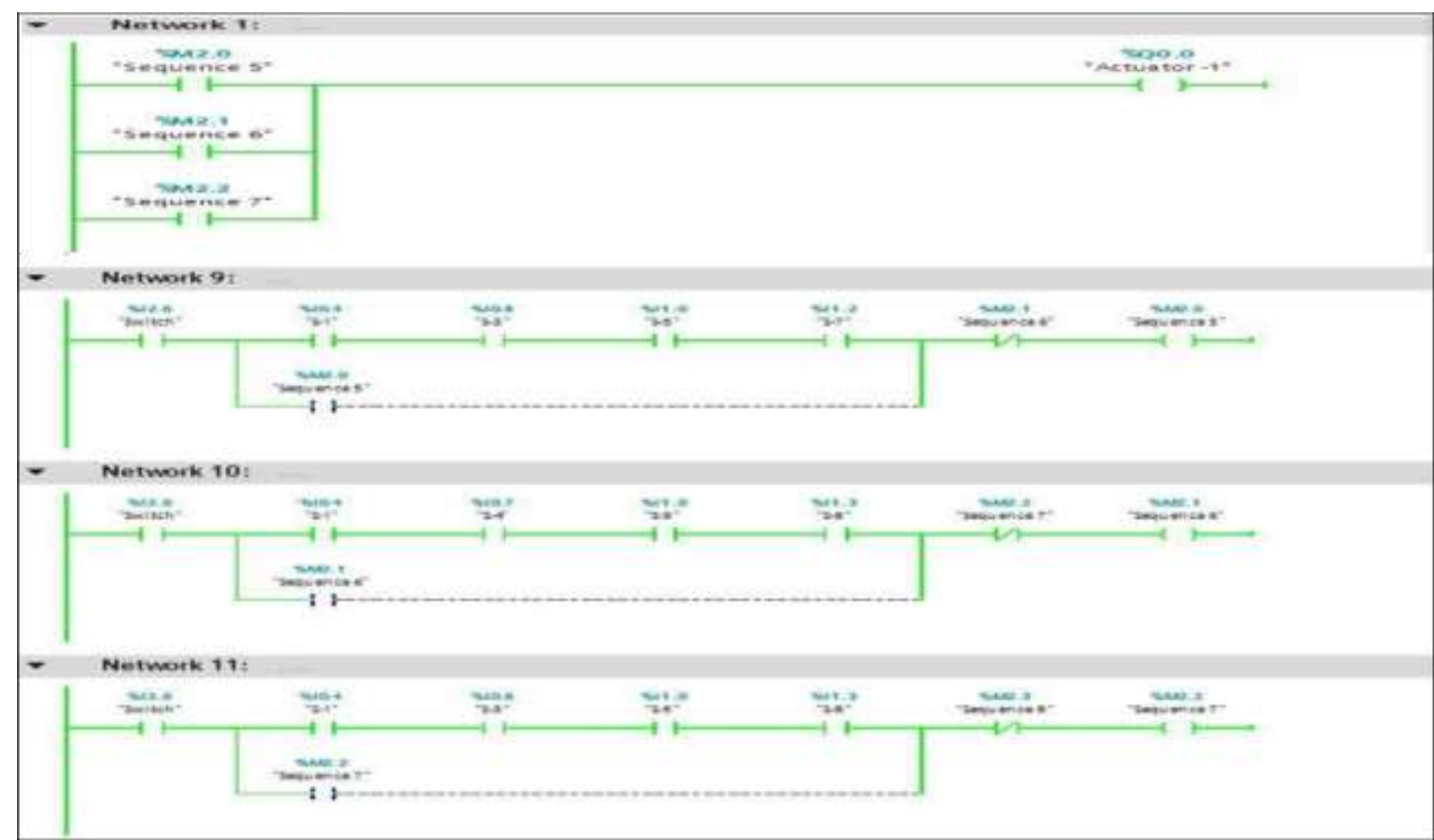

Figure (6): Ladder diagram operated actuator-1.

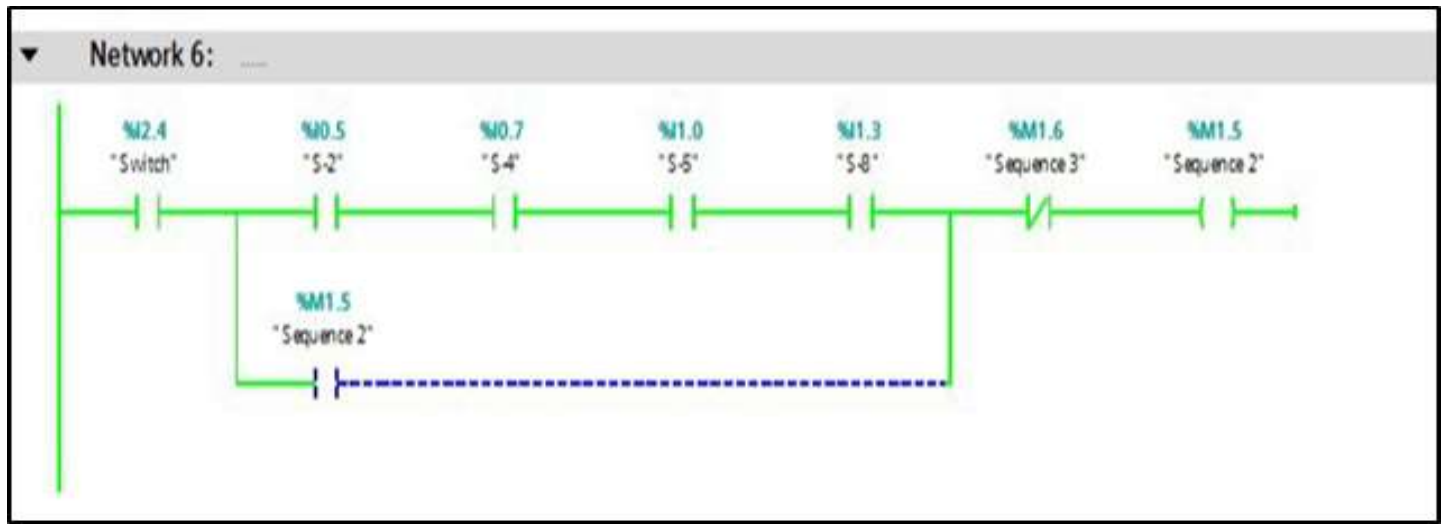

Figure (7): Ladder diagram of sequence 2. 
Table (3): Addressing and description of the enhanced sequence for the first obstacle (YZ).

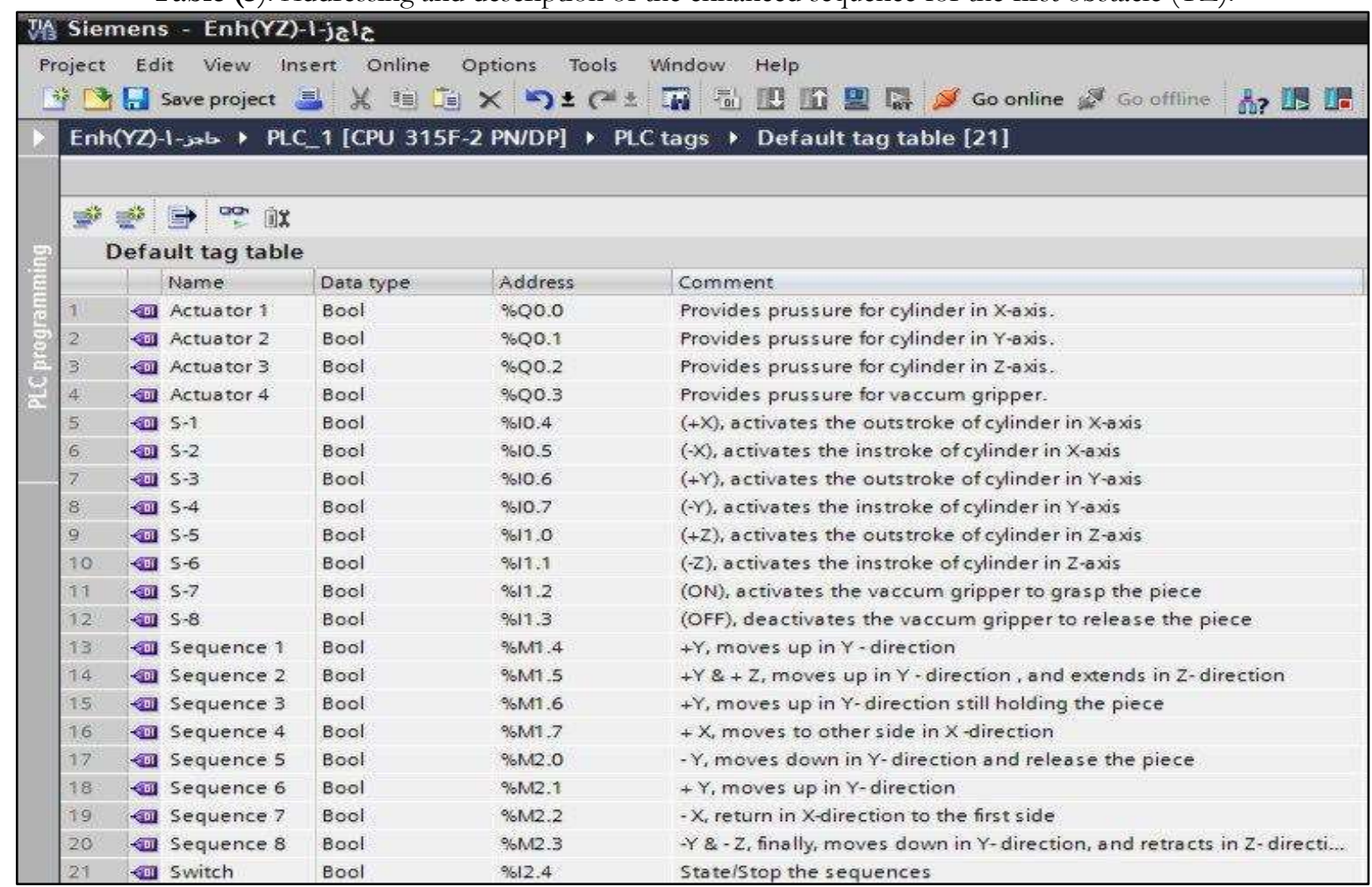

Table (4): Addressing and description of the reference sequence for the second obstacle.

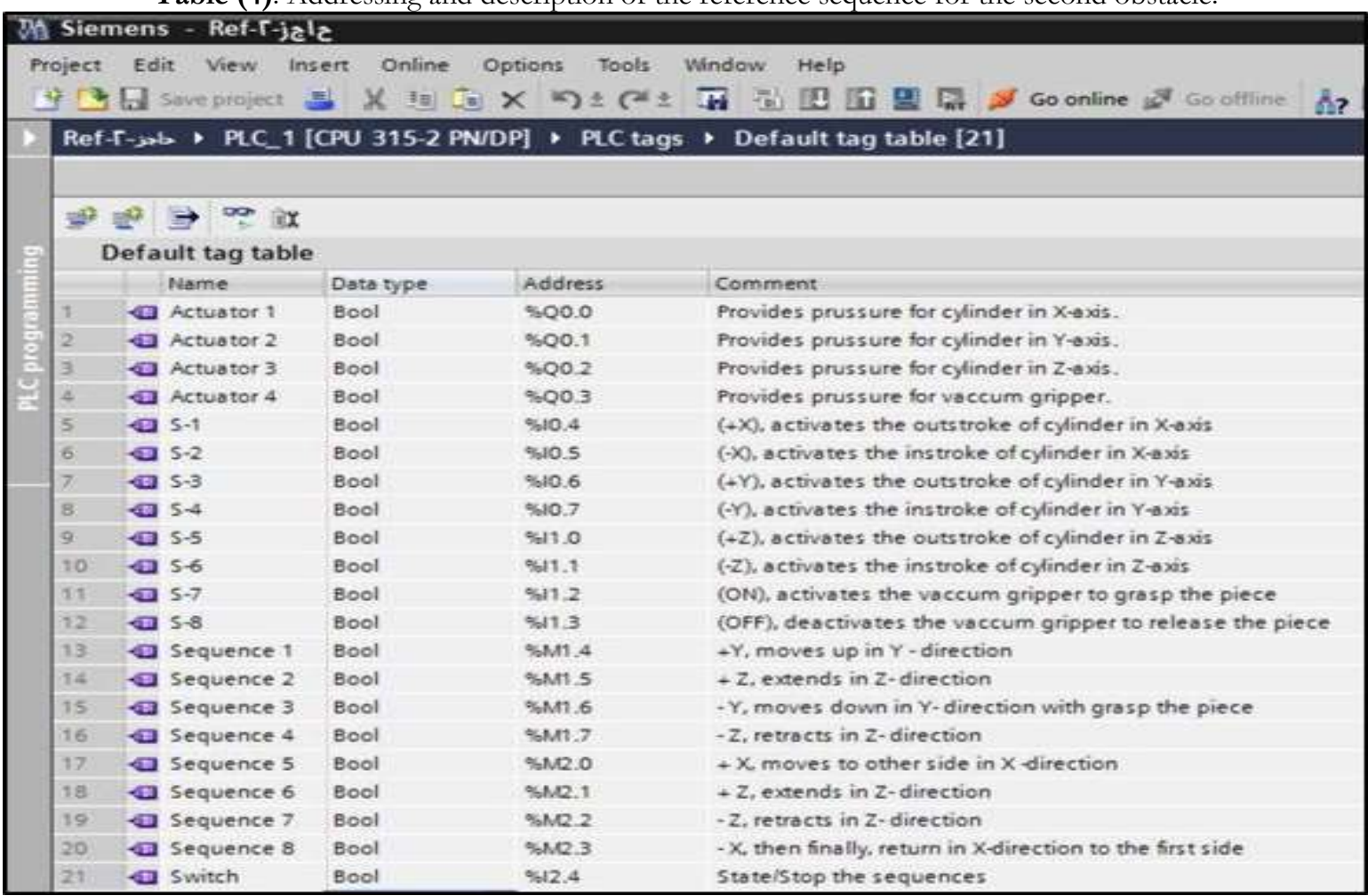


Table (5): Addressing and description of the enhanced sequence for the second obstacle (YZ)

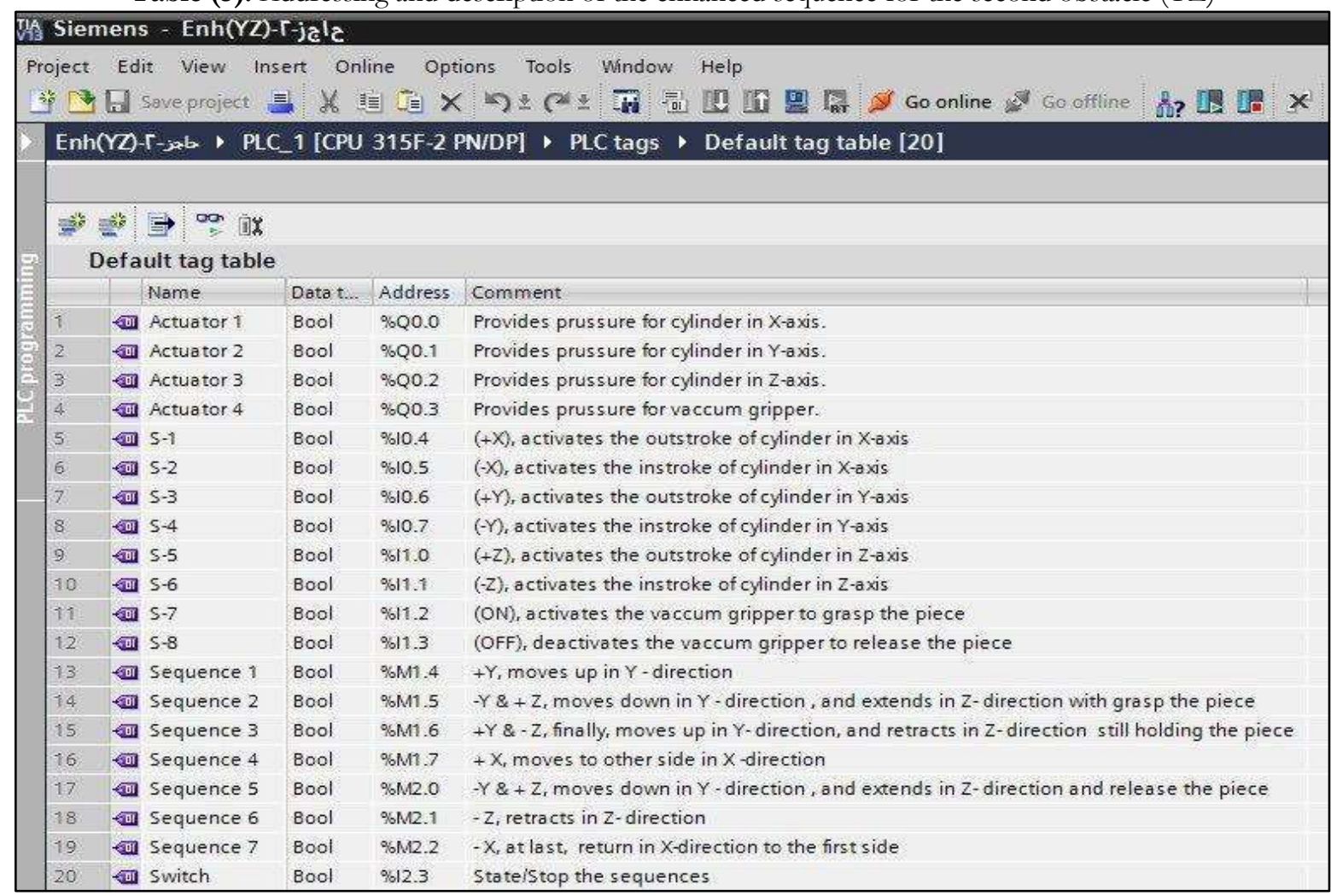

\subsubsection{Calculations for double-acting} pneumatic cylinder

Firstly, need to calculate the geometry of the cylinder by using equations below; as illustrated in figure (8).

$$
\begin{gathered}
A_{\text {piston }}=\frac{\pi d_{1}^{2}}{4 \times 100} \ldots \ldots \text { (1) } \\
A_{\text {rod }}=\frac{\pi d_{2}^{2}}{4 \times 100} \ldots \ldots \ldots \text { (2) } \\
A_{\text {annulus }=} A_{\text {piston }}-A_{\text {rod }} \ldots \ldots \text { (3) }
\end{gathered}
$$

Where,

A piston: Piston area, $\mathrm{cm}^{2}$

A rod: Piston rod area, $\mathrm{cm}^{2}$

A_ (annulus): Piston annulus - ring shape area- area, $\mathrm{cm}^{2}$

d1: Piston diameter, $\mathrm{mm}$.

d2: Rod diameter, $\mathrm{mm}$.

- Extending velocity and flow rate calculation: As shown in figure (9), the affecting area is the piston area of cylinder, using equation (4)

$$
Q=A_{\text {piston }} \cdot v \cdot 6 \ldots . . .(4)
$$

Q: Flow rate for the extending cylinder, $\mathrm{L} / \mathrm{min}$.

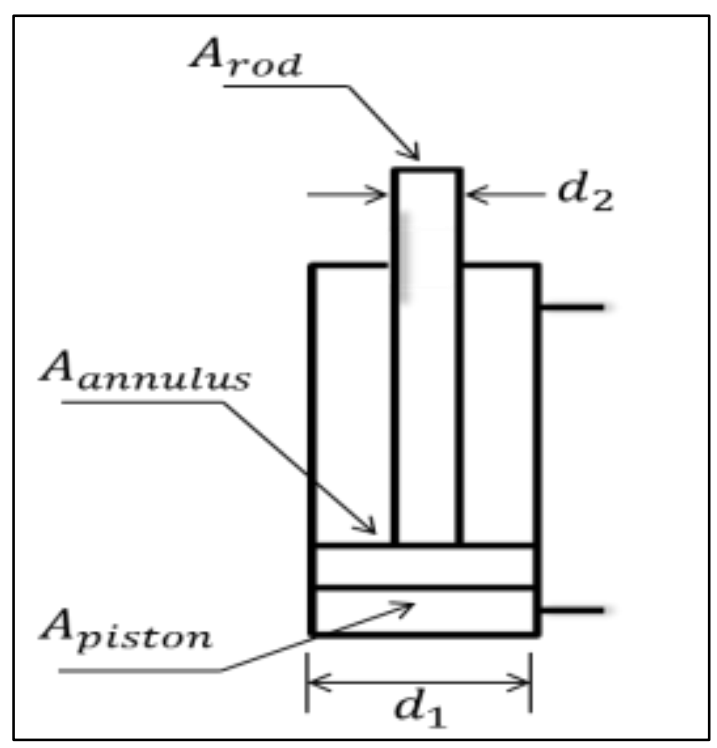

Figure (8): Cylinder geometry

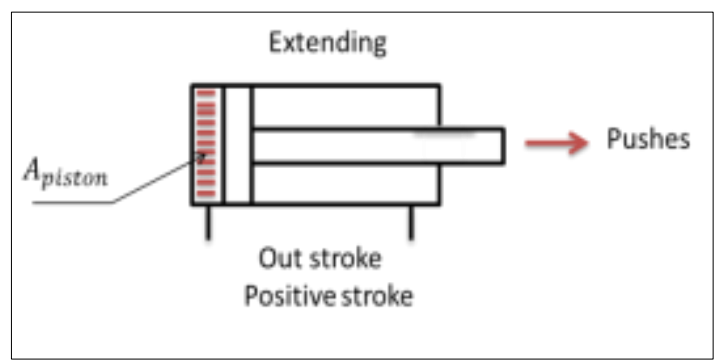

Figure (9): The extend state of the cylinder

- Retraction velocity and flow rate calculation: As shown in figure (10), the piston rod area is the affecting area, by equation (5) 


$$
Q=A_{\text {annulus }} \cdot v .6 \ldots . . .(5)
$$

To calculate the velocity of the pneumatic cylinder using equation (6)

Where,

$$
v=\frac{s}{t \times 100}
$$

$\mathrm{v}$ : Velocity of the pneumatic cylinder, $\mathrm{m} / \mathrm{sec}$.

$\mathrm{s}$ : Stroke of the pneumatic cylinder, $\mathrm{mm}$.

t: Passed time for the pneumatic cylinder, sec.

In the case of calculating the full path velocity of each sequence, the stroke is replaced by a distance and the time taken is the time of the total distance of the sequence not one stroke time as in the equation (7)

$$
v=\frac{D}{T \times 100} \ldots \ldots
$$

Where,

$\mathrm{v}$ : Velocity of the sequence, $\mathrm{m} / \mathrm{sec}$.

$\mathrm{D}:$ Distance of the path sequence, $\mathrm{mm}$.

$\mathrm{T}$ : Passed time for the sequence, sec.

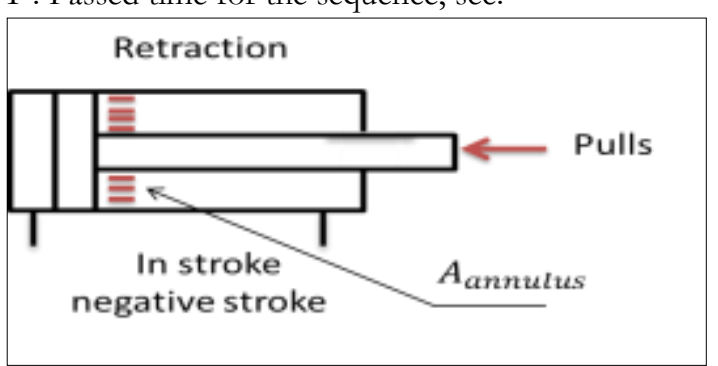

Figure (10): The retract state of the cylinder

The distance, time, and velocity for each sequence in the pick and place system are important parameters in this work to determine the optimization sequence according to these parameters. In figure (11), shows the circuit of each cylinder connects and how it works.

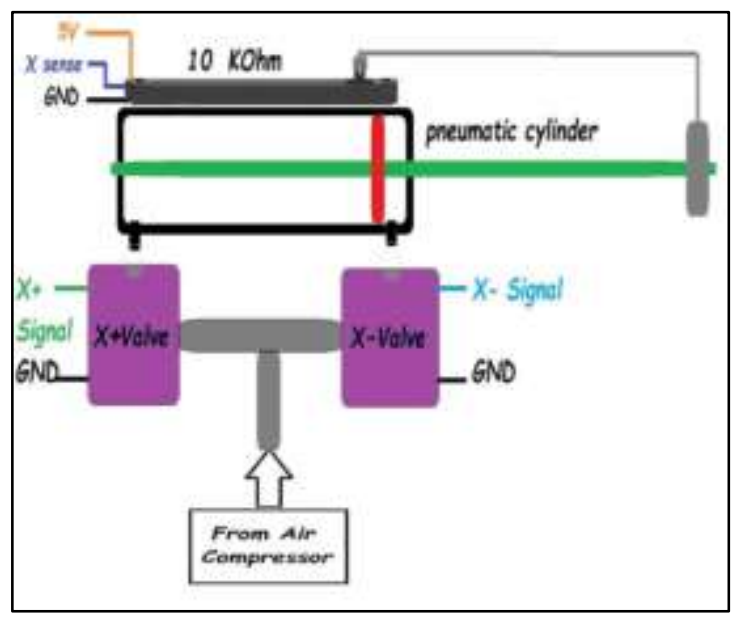

Figure (11): Cylinder circuit

\subsubsection{Calculations for Distance and Time of the sequences}

In this work, there are three planes $\mathrm{XY}$ plane, $\mathrm{XZ}$ plane, and $\mathrm{YZ}$ plane. In these planes the $3 \mathrm{D}$ movement of the pick and place pneumatic system occurs, this movement is represented as a displacement vectors. The value of these displacement vectors is equal to the stroke of the pneumatic cylinder, as for the direction of these vectors, it different from one sequence to another.

To calculate the distance of each sequence consisting of several displacement vectors, vector summation methods are used in all planes as illustrated in figure (12).

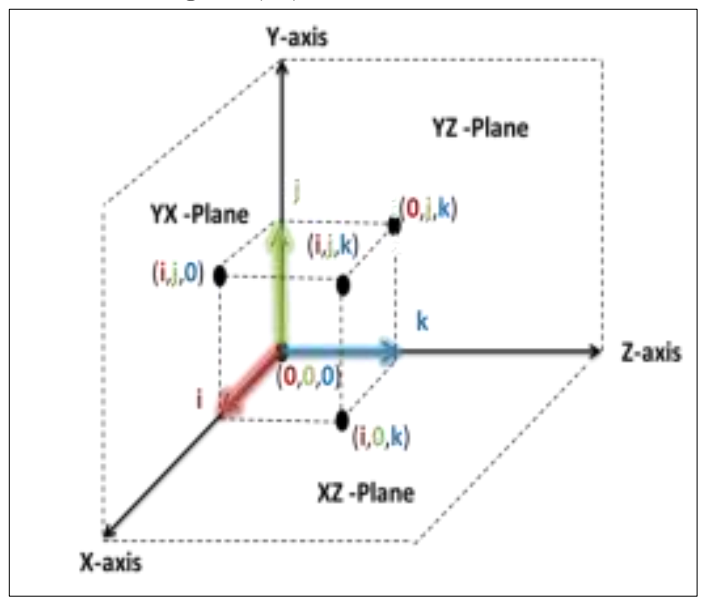

Figure (12): X (i), Y (j), Z (k)-planes.

These outcomes are combined using an array that represents final distance calculation for each sequence, and make a comparison with each other, as follows;

$$
D=\sum_{1}^{n} \text { Sequence }_{n} \ldots . .(8)
$$

$$
\begin{gathered}
\text { Sequence }_{n}=(x i+y j+z k) \ldots(9) \\
T=\sum_{1}^{n} t_{\text {sequence }_{n}} \ldots \text {... (10) }
\end{gathered}
$$

D: Distance of the sequence, $\mathrm{cm}$

$\mathrm{T}$ : Time passed of the sequence, sec

n: Number of sequence steps

$\mathrm{n}=1 \ldots 10$; for the reference sequence of the first obstacle

$\mathrm{n}=1 \ldots 8$; for the enhanced sequence of the first obstacle, and for the reference sequence of the second obstacle

$n=1 \ldots 7$; for the enhanced sequence of the second obstacle

$n=1 \ldots 6$; for the enhanced sequences of the first, and the second obstacle.

The processes which have a number of sequences 10,8 , and 7 are compensated at a constant velocity for all extends cylinders and retracting them, but at a variable velocity in any axis of the three axes, the process of this case is used 6 sequences.

\subsection{PLC-based control the sequences}

The system is centrally controlled by a PLC controller, which every input and output data are fed in the controller. The control processes information that happens in the input and output components of the pick and place pneumatic system. Input components are linear potentiometers that corresponded as sensors. The controller is electrically generated by a voltage power supply of $24 \mathrm{~V}$ DC. Pick and place pneumatic system movement is powered by a compressed air. Figure (13) shows, the mechanism of the proposed system. In feedback controller, the output of the system is fed back through a linear 
potentiometer measurement to the reference value. Since the input and the output components are directly connected to the controller, the feedback connection of the sensor from the output cannot be seen externally.

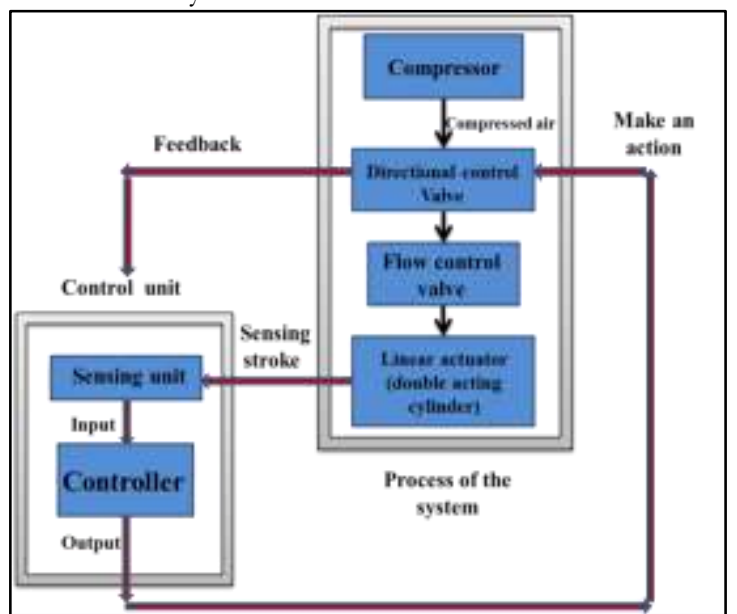

Figure (13): Flow Diagram of mechanism.

\section{Results and Dissections}

In this research, the results are presented and discussed, it is explained how to reduce the sequence of the system process and thus choose the best sequence that the system takes in moving the product from one location to another through several comparisons between these sequences.

In addition to calculating the time of each of these sequences by establishing the compressed air velocity in the pneumatic system and recalculating the time when changing the system velocity and synchronizing the axes.

As shown in figures $(14,15$, and 16), shows the difference distance, time, and velocity among the processes for both obstacles.

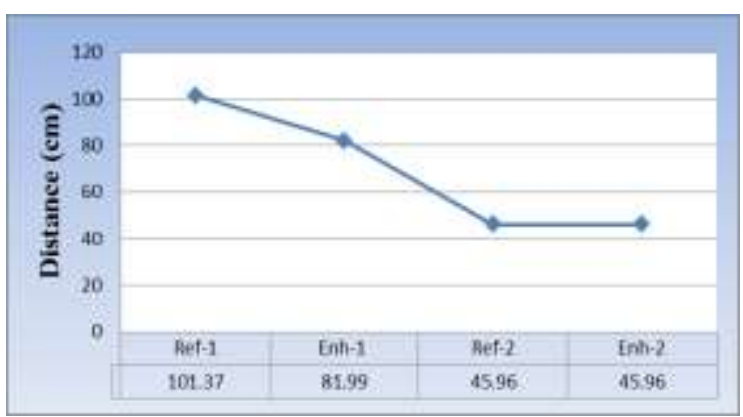

Figure (14): Comparison among all sequences for both obstacles in terms of distance.

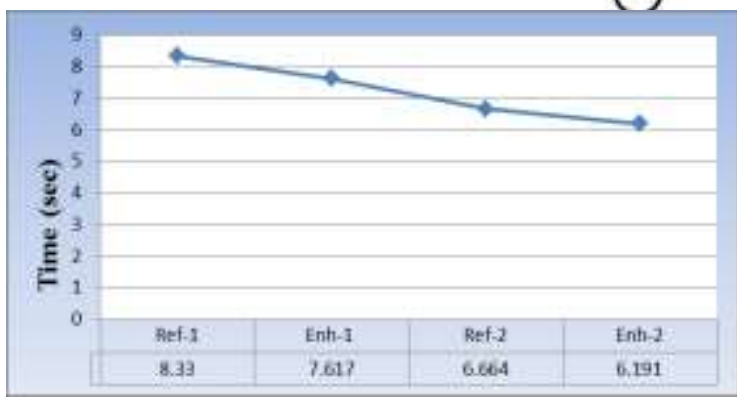

Figure (15): Comparison among all sequences for both obstacles in terms of time.

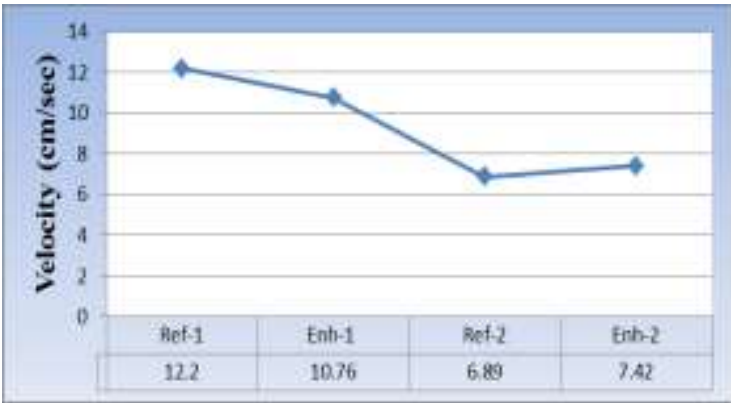

Figure (16): Comparison among all sequences for both obstacles in terms of velocity.

This research first intended to identify the most suitable sequences to achieve pick and place process problem which chosen as a case study. Optimization of sequence selection has been carried out by controlling with PLC. Therefore, selection of an optimal sequence is based on the obtained results of actual real state of the reference sequence for both obstacles (Ref-1, Ref-2) and compared it along with two other suggested enhanced sequences (Enh-1) for the first obstacle, and (Enh-2) for the second obstacle. Therefore, as shown in Table (7), analysis of final result of all enhanced sequences shows that solutions of selection of the best sequence are feasible and guaranteed.

The results of all enhanced sequences have been compared the reference sequence for both obstacles in terms of minimizing of traveled distance was about $(19.78 \%, 0 \%)$ for (Enh-1YZ), and (Enh-2 YZ), respectively, that is lead to minimizing of transport time was about $(9 \%, 7 \%)$ for (Enh-1YZ), and (Enh-2 $\mathrm{YZ})$, respectively. Thus, these results have direct impact on the velocity that can be expected about $(12 \%, 8 \%)$, for (Enh-1YZ), and (Enh-2 YZ), respectively. 
Table (7): Relationships of the Difference Parameters and Percentage \%

\begin{tabular}{|c|c|c|c|c|c|c|c|}
\hline \multirow{2}{*}{ Sequence } & \multicolumn{6}{|c|}{ Difference Parameters and Percentage \% } & \multirow[b]{2}{*}{$\begin{array}{c}\text { No. } \\
\text { Sequences }\end{array}$} \\
\hline & $\begin{array}{c}\Delta \text { Distance } \\
(\mathrm{cm})\end{array}$ & $\begin{array}{c}\text { Percentage } \\
\%\end{array}$ & $\begin{array}{c}\Delta \text { Time } \\
(\mathrm{sec})\end{array}$ & $\begin{array}{c}\text { Percentage } \\
\%\end{array}$ & $\begin{array}{r}\Delta \text { Velocity } \\
(\mathrm{cm} / \mathrm{sec})\end{array}$ & $\begin{array}{c}\text { Percentage } \\
\%\end{array}$ & \\
\hline $\begin{array}{c}\text { Ref-1 \& } \\
\text { Enh-1 }\end{array}$ & 19.38 & $19 \%$ & 0.713 & $9 \%$ & 1.44 & $12 \%$ & 2 \\
\hline $\begin{array}{c}\text { Ref-2 \& } \\
\text { Enh-2 }\end{array}$ & 0 & $0 \%$ & 0.473 & $7 \%$ & 0.53 & $8 \%$ & 1 \\
\hline
\end{tabular}

\section{Conclusion}

Successful design and fabrication of the pick and place pneumatic system that was used to control the pneumatic cylinders movement in $3-\mathrm{D}, \mathrm{x}, \mathrm{y}$, and $\mathrm{z}$ axes. Each sequence contains a set of steps and it is required to reduction in the number of these steps. Compared with a reference sequence, the optimum sequence with minimal steps has been addressed for each obstacle.

This application can be used with some production lines in simple hydraulic stations which have simple operations since it does not require high pressure. Also, the proposed system in not expensive

and easy to maintain which promote it for wide range of industrial applications require automation.

\section{References:}

[1]K. Dutt, "Analytical description of pneumatic system”, Int. J. Sci. Eng. Res., vol. 4, no. 9, pp. 1443-1453, 2013

[2]M. C. SMITH, "The positioning of a low friction pneumatic actuator using on-off control", 1987.

[3]A. Al-mesaody, "Programming a pneumatic processes sequence based on plc by demonstration", Al-Khwarizmi Eng. J., vol. 13, no. 3, pp. 46-54, 2017.

[4]G. Figliolini, P. Rea, and G. Di Biasio, "Design and test of pneumatic systems for production automation" [5]R. Pawar and N. R. Bhasme, "Application of PLC ' $\mathrm{s}$ for automation of processes in industries," Rahul Pawar. Int. J. Eng. Res. Appl., vol. 6, no. 6, pp. 53-59, 2016.

[6]S. Kazemi and H. Kharrati, "Visual processing and classification of items on moving conveyor with pick and place robot using PLC," Springer Singapore, 2017.

[7]L. Alboteanu, G. Manolea, and F. Ravigan, "Automatic sorting and handling station actuated by pneumatic drive", University of Craiova / Department of Electromechanical, Environmental and Applied Informatics, Craiova, Roma-, pp 1-8, 2018.

[8] T.Dewi, et al, "Inverse kinematic analysis of 4 DOF pick and place arm robot manipulator using fuzzy logic controller", International Journal of Electrical and Computer Engineering (IJECE), Vol.10, No.2, pp. 1376 1386, 2020.

[9] S. A. Namekar, and R. Yadav, "Programmable Logic Controller (PLC) and its Applications",
International Journal of Innovative Research in TechnologY (IJIRT), Vol. 6, No. 11,2020.

[10] S. S. Khaleel, et al, "Arduino-Based Controller for Sequence Development of Automated Manufacturing System", Al-Khwarizmi Engineering Journal, accepted in: 5-7, 2020.

[11] H. Hadi, M. Salloom, "pneumatic control system of automatic production line using SCADA implement PLC," Al-Khwarizmi Engineering Journal, vol.15, no.3, pp. 16-28, 2019. 